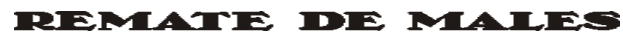

Campinas-SP, v.39, n.1, pp. 28-37, jan./jun. 2019

\title{
OS MUSEUS SÃO RIOS
}

\section{MUSEUMS ARE RIVERS}

\author{
Davi Pessoa ${ }^{1}$
}

Resumo: $\mathrm{O}$ ensaio confronta a concepção de museu através de pressupostos iconológicos e icnológicos, seguindo um fluxo teórico que passa por Cesare Brandi, Marcel Proust, Paul Valéry, Theodor Adorno, Michael Taussig, Tarsila do Amaral, entre outros, com o intuito de pensar os museus a partir de um novo uso.

Palavras-chave: museu; arte; crítica.

Abstract: The essay confronts the conception of museum through iconological and icnological presuppositions, following a theoretical flow that passes through Cesare Brandi, Marcel Proust, Paul Valéry, Theodor Adorno, Michael Taussig, Tarsila do Amaral, among others, with the intention to think museums from a new use.

Keywords: Museum; Art; Critical.

"Só posso chamar assim porque essa dor só aparece quando percorro museus. Mal começo a caminhar e a parar diante dos quadros vem a dor no ombro esquerdo - é sempre a mesma. Gostaria de saber do que se trata. É dor de emoção?”

("Dor de museu”, Clarice Lispector)

Cesare Brandi, historiador e crítico de arte, mais conhecido entre nós por seu estudo acerca da Teoria da restauração, de 1963 (publicado no Brasil apenas em 2004), passa a trabalhar junto à Unesco, em 1948. Por isso passa a fazer inúmeras viagens pelo mundo para estudar as singularidades

1 Professor adjunto de Língua e Literatura Italiana do Departamento de Letras Neolatinas (LNEO), Universidade do Estado do Rio de Janeiro (UERJ): < davipessoacarneiro@gmail.com>. 
do patrimônio artístico e cultural de certas culturas. Poucos anos antes, tornava-se fundador e diretor do Instituto Central de Restauração (ICR), de Roma, e de 1947 a 1950 fundou e dirigiu a revista L'Immagine, que chegou a ter 16 números e que reunia artigos de crítica literária e de arte, filosofia, política etc.

Brandi considerava a revista um "diário público", e precisamente a partir de diários de viagens, compartilhou com os leitores muitas de suas reflexões sobre o Egito, a Sićlia, a Grécia, a Rússia, em livros que publicou, como: Città del deserto, Diario cinese, Pellegrino in Puglia, Persia mirabile, Sicilia mia, Viaggio nella Grecia antica, A passo d'uomo e Verde Nilo. Este último, publicado em 1991, é o relato de sua experiência de viagem ao Egito, no início dos anos 1960, durante o período do governo do general Gamal Abdel Nasser. Brandi (1991, p. 7) abre seu diário com a seguinte ressalva: "O Egito não é um país, é um rio".

Para sua decepção, durante a estadia nesse país, não conseguiu ver o "verde do Nilo", tão retratado por pintores, já que tal fato ocorre apenas uma vez por ano e em outra época que não a de sua viagem. E se o verde, e não o azul do céu e das águas, é o que vem à tona quando se lembra desse rio, porém, quando visto de perto, ele não é verde nem azul, pois ele - na concepção de Brandi (1991, p. 3) - é um rio de lama. Esse rio de lama, de pouca visibilidade, parece ser a imagem que ele (p. 122) viu, do mesmo modo, no Museu: "Do Museu do Cairo não se pode dar uma ideia a não ser a partir do modo mais irreverente: é como um magazine do tipo Upim ou Standa". $\mathrm{O}$ autor acrescenta: "A constipação dos objetos é tal que nos deixa sem respiração" (p. 122). Mas era justamente nessa desordem que Brandi (p. 123) via o fascínio daquele Museu:

Talvez não queira jamais ver o Museu do Cairo ordenado, no qual entre as
imensas riquezas que estão ali amontoadas, é necessário descobrir por si só
aquilo que mais se procura ou se ama, onde os ornamentos da apresentação ou
da museografia não tentam elevá-las ou transformá-las ao gosto moderno. Se
algo resiste naquele estado de assédio ou consegue emergir daquele empurra-
-empurra dominical, é realmente uma obra-prima.

Assim, o Museu do Cairo, como aponta Brandi (1991, p. 125), abre um rastro profundo na percepção, já que se encontra "desfolhado, na memória,

2 UPIM - Unico Prezzo Italiano Milano - era uma cadeia de grandes magazines, fundada em 1928, nos quais os artigos eram vendidos por 1 a 5 liras. 
de todo aquele fervilhamento de objetos, pelas inumeráveis curiosidades históricas que sufocam as obras de arte".

Ainda nos anos 1960, Brandi viajou para a Rússia, movido pelo desejo de conhecer o museu Hermitage, em São Petersburgo, e a Catedral Santa Sofia, em Kiev. O autor se questiona se é possível conhecer bem os cinco quilômetros de salas do museu, com seu formato panorâmico e circular, além das "dificuldades que aumentam se se considera que faltam os catálogos, e que as plaquinhas são escritas em russo" (BRANDI, 1970a, p. 57). Outro detalhe lhe chamou a atenção: enquanto na Itália os museus estão sempre repletos de turistas, naquele período o Hermitage estava abarrotado de estudantes russos, os quais cultivavam amor pela arte, mesmo no período de férias, portanto não se tratava de visitas escolares, como um guia do museu lhe informou.

Em 1969, o autor relata outra experiência que escapa a estas duas posições aqui brevemente apresentadas (do Museu do Cairo e do Hermitage): trata-se do Museu de Giacomo Manzù, em Ardea, região do Lazio, próxima a Roma. Brandi (1976, p. 379) diz que "é único em seu gênero, na Itália, não por uma única razão, e isso bastaria, mas também não só por uma única razão". O museu contém obras de um artista vivo e em atuação, como o qualifica o autor: "Uma espécie de ateliê aberto ao público, portanto algo que não faz apenas rememorar o passado, mas que se lança em direção ao futuro, está aberto no futuro" (p. 379). Ao contrário do esperado reconhecimento do gesto - a doação de mais de 400 esculturas ao Museu, organizado por um grupo de amigos e pela companheira de Manzù, Inge Schabel -, o Estado aplica a lei de cobrança de mais impostos, enquanto, como destaca Brandi (p. 380), "as doações ao Estado, de obras de arte, são raras como os cometas, e sempre mais raras serão". O autor ainda ressalta que tal tipo de museu irá atrair um público diferente, pois é o museu vivo de um artista que vive "no passado, no futuro, ou em seu tempo que é a fusão de ambos, porque tal é a posição de Manzù". E porque ali se vive "no presente da obra de arte, enquanto nosso presente ou já é passado ou é já futuro" (p. 381).

A partir dessas três experiências de Cesare Brandi, acredito que podemos reabrir o ensaio de Theodor Adorno, "Museu Valéry Proust", escrito em 1953 e publicado na revista literária Die Neue Rundschau. Esse autor irá evidenciar a relação entre museu e mausoléu, pois os "museus são como sepulcros de obras de arte, testemunham a neutralização da cultura” (ADORNO, 1998, p. 173), sendo que o valor de mercado retira a felicidade 
de contemplação, mesmo se as obras forem expostas em seu "ambiente natural”. Aliás, como ele aponta, é ainda mais penoso neste último caso do que a exposição em museus, porque a "sofisticação provoca mais danos à arte que o colecionismo" (p. 173), ou ainda, "a modernização do passado violenta e danifica o passado” (p. 174). Adorno irá se valer das posições de Paul Valéry e de Marcel Proust para travar uma disputa intelectual acerca dos museus, e, em particular, no que diz respeito ao Louvre.

Valéry (2008, p. 32), em "O problema dos museus" [Le problème des musées], ensaio publicado em 1931, inicia seu relato com a afirmativa negativa: "Não gosto tanto dos Museus". Qual seria o intuito de visitá-los, portanto? Questiona-se Valéry:

Vim instruir-me ou buscar encantamento, ou, de outro modo, cumprir um dever e satisfazer convenções? Ou, ainda, não seria este um exercício de tipo particular, passeio bizarramente travado por belezas e desviado a cada instante por tais obras-primas à direita eà esquerda, em meio às quais é preciso conduzir-se como um bêbado entre balcões? (VALÉRY, 2008, p. 32).

Ali, na "casa da incoerência", na perspectiva da leitura de Adorno (1998, p. 175) em torno das colocações de Valéry, este, como espectador, "se preocupava muito pouco com a crítica da economia política", isto é, centrada na superacumulação de obras de arte no Louvre. No entanto, embora não faça tal crítica, Adorno (1995, p. 176) aponta que essa mesma superacumulação irá produzir no poeta francês uma "vertigem do museu", fazendo com que, mesmo depois de sair daquele espaço vertiginoso, ele não consiga "libertar-se do magnífico caos do museu - uma parábola, poder-se-ia dizer, da anarquia da produção de mercadorias na sociedade burguesa desenvolvida - e procur[e] a razão de seu mal-estar".

A posição de Valéry se mostra, então, bem distinta daquela de Brandi, quando de sua visita ao Museu do Cairo. Escreve o francês:

De fato, creio que nem o Egito, nem a China, nem a Grécia, que foram sábios e refinados, conheceram tal sistema de justapor produções que se devoram umas às outras. Nenhum deles dispunha unidades de prazer incompatíveis sob números de registro e segundo princípios abstratos. Mas nossa herança é esmagadora. O homem moderno, extenuado pela enormidade de seus meios técnicos, se empobrece pelo excesso mesmo de suas riquezas (VALÉRY, 2008, p. 32).

Para ele, o excesso produz vertigem, mal-estar:

O magnífico caos do museu me segue e se combina com o movimento da rua fervilhante. Meu mal-estar busca sua causa. Ele observa ou inventa - não 
conheço a relação entre essa confusão que o obseda e o estado atormentado das artes de nosso tempo (VALÉRY, 2008, p. 33).

Brandi, por outro lado, vê no excesso o meio pelo qual o homem é chamado a tomar posição, isto é, a desativar o acúmulo de tradições a partir da intersecção de passado, presente e futuro, que há no gesto de buscar entrever o que se encontra obliterado pelo amontoado de objetos. Assim, ao contrário de sucumbir ao "museal", ao mausoléu, o museu pode também ser pensado em nosso presente como espaço em que se trabalha incessantemente o luto da "Mãe Arquitetura". E, ainda, como ele discute, no ensaio "La perdita del futuro" (BRANDI, 197ob, p. 121): "Na realidade, a redução ao presente está longe de acalmar ou extinguir a angústia que a condição humana traz desde seu nascimento, e abolir o futuro não significa abolir a morte".

Marcel Proust, em À sombra das moças em flor, segundo volume de Em busca do tempo perdido, relaciona a estação de trem ao museu. E, como argumenta Adorno (1998, p. 177), Proust os compara porque:

Ambos estão afastados do contexto superficial dos objetos da atividade prática, e a isso poderíamos acrescentar que ambos são portadores de um simbolismo de morte: a estação, do antigo simbolismo da viagem; o museu, daquele que se refere à obra, o universo novo e perecível criado pelo artista.

Adorno (1998, p. 181) diferencia o artista horrorizado (Valéry) do consumidor deslumbrado (Proust), o qual flana pela exposição, e em "seu olhar maravilhado, Proust salva para si um pedaço da infância; Valéry, por outro lado" - na perspectiva de Adorno , "fala da arte como um adulto", visto que lê a morte das obras de arte no museu como um despertar para a vida: "o que se chama posteridade, é a vida póstuma das obras". Interessante perceber a leitura um tanto conservadora de Adorno - e não a de Valéry, como aquele deseja nos fazer crer.

Se há realmente uma vida póstuma das obras, ela parece muito mais possível a partir de uma abertura à infância, ou seja, abrindo-se possibilidade para um novo uso dos museus, pois - como aponta Giorgio Agamben (2007, p. 73), em "Elogio da profanação" - "a impossibilidade de usar tem o seu lugar tópico no Museu. A museificação do mundo é atualmente um dado de fato". Se tudo hoje, portanto, pode tornar-se museu, seja Veneza, seja a língua portuguesa, seja até mesmo o "amanhã", é porque cada vez mais entramos em museus com paredes muito bem erguidas (e não ao modo dos Museus sem paredes de Malraux), nos 
quais se impõe a impossibilidade de usar, de fazer experiência. A experiência se realiza, então, no deslocamento pelos museus-mundo, ao modo de Brandi, mas também de Italo Calvino, com sua Coleção de areia, ou ao modo de Pasolini em $O$ cheiro da Índia e em $A$ longa estrada de areia, ou no deslocamento de pequenos museus pelo mundo?

Tarsila do Amaral (2008, p. 631) publicou no Diário de São Paulo, em 1947, "Um pequeno museu", texto em que analisa uma exposição que vinha da velha Europa "à novíssima Avenida Europa de São Paulo" para habitar a casa de número 408. O pequeno museu era composto por uma coleção de quadros, móveis e objetos vindos da Itália, e Tarsila via nessa mostra de arte algo agradável, "tudo se acha distribuído numa residência particular com verdadeiro espírito estético, longe da monotonia das coleções classificadas" (AMARAL, 2008, p. 631). E, ainda mais:

São Paulo está de parabéns. Apresenta-se agora a oportunidade única de se verem em contato com um pequeno museu de arte séria todos os que, embora possuindo fortuna, não podem viajar por se acharem presos aqui aos afazeres, privados assim dos ambientes artísticos que nós estamos longe de possuir" (AMARAL, 2008, p. 631).

O fortunado era o conde Rodolfo Crespi (empresário da indústria do algodão, "Cotonifício Rodolfo Crespi”), situada na Rua dos Trilhos com a Rua Taquari. Crespi foi também fundador da Banca Italiana di San Paolo, que depois viria a se tornar a Banca Francese e Italiana per l'America del Sud, predecessora do Banco Sudameris, além de fundador do jornal Il Piccolo, com linha editorial simpática ao fascismo de Mussolini. O que há por trás desse suposto fazer experiência?

Cada vez mais pequenas mostras viajam pelo mundo, quase como uma prateleira de supermercado na qual quase tudo está em falta, e habitam museus, nos quais turistas - longe de serem aprendizes - pagam bilhetes caros e "veem" as mostras através da lente de uma máquina fotográfica ou de um celular, quase como se tornassem este um utensílio obrigatório para ver exposições. A que exigências estamos dispostos a responder? Se Valéry via uma biblioteca anexada ao museu, e se ali Vênus era transformada em documento, então, parece que aos livros, documentos e arquivos, algumas curadorias, hoje, estão voltadas. Como se o dar a ler trouxesse uma nova possibilidade de uso ao dar a ver.

Acredito, assim, que há algo no "anteprojeto", escrito por Mário de Andrade, para uma possível "Enciclopédia brasileira" que pode nos ajudar a pensar um novo uso para o museu. O convite lhe havia sido feito pelo 
ministro Capanema, em 1939, quandoescritorassumira ocargo de consultor técnico do Instituto Nacional do Livro. O "anteprojeto" se tornou, como sabemos, um "antiprojeto", visto que naufragou não apenas nas mãos de burocratas incompetentes, mas também nas próprias impossibilidades de criar, naquele instante, algo que conjugasse cultura erudita e popular (multivalente, nas palavras de Mário). Tal enciclopédia deveria viver "nos lares operários”, visto que neles não havia (e ainda não há!) a presença de uma boa biblioteca, ou como Mário (ANDRADE, 1993, p. 4) argumenta: "Porque, por si mesma, uma boa enciclopédia é toda uma biblioteca".

Assim, ao contrário da simbologia, ou da iconologia, que dá a ver e a ler o caráter monumental de uma enciclopédia, cuja ossatura se torna rígida mediante o plano que a sedimenta, Mário buscava um plano elástico, flexível, em que a multiplicidade de problemas pudesse confrontaros restos, as lacunas (a icnologia, o saber dos restos), aquilo que é habitualmente colocado de fora dos projetos institucionais. "Por tudo isso", aponta o autor, "parece que o ideal de uma enciclopédia brasileira nossa contemporânea será pretender uma aparentemente ambiciosa multivalência" (ANDRADE, 1993, p. 20). Ainda: "Abrangerá todas as camadas de cultura de leitores possíveis, dando a cada assunto ou verbete um peso cultural diverso, de acordo com a sua própria área intelectual de vida" (p. 24).

O gesto icnológico (e não iconológico) lê sempre uma imagem relacionada à outra. Muitos séculos antes, Dante Alighieri, por volta de 1303 e 1306, compôs o Convívio, isto é, um banquete de sabedoria voltado a homens e mulheres famintos de saberes. Havia, desse modo, um desejo transmitido em língua vulgar a um novo público - laico -, que não tinha conhecimentos de latim, mas ao qual não faltava "bondade de espírito" para participar do banquete enciclopédico. Mário ouviu de muitos amigos que seu gesto era semelhante àquele de Dante, interpretação da qual, no entanto, se esquivava, dizendo, na apresentação à Gramatiquinha brasileira:

Muita gente, até meus amigos, andaram falando que eu queria bancar o Dante e criar a língua brasileira. Graças a Deus não sou tão ignorante nem tão vaidoso. A minha intenção única foi dar a minha colaboração a um movimento prático de libertação importante, necessária (ANDRADE, 1993, p. XII).

Outro gesto interessante encontramos em My Cocaine Museum, de Michael Taussig, publicado em 2004. Nesse fabuloso estudo, esse 
antropólogo relaciona questões coloniais vinculadas à fundação do Museu do Ouro, em Bogotá. Em 1939 - mesmo ano em que Mário de Andrade recebeu o convite de Gustavo Capanema -, o Banco da República da Colômbia adquiriu o misterioso "poporo quimbaya", peça de extraordinária beleza, com a qual se deu início à coleção do Museu. Este, apesar de exibir em sua coleção essa peça de ouro, silenciava diante do fato de que, por mais de três séculos de ocupação espanhola, a colônia usufruiu do trabalho de escravos africanos em suas minas desse metal precioso. $\mathbf{O}$ ouro, assim, determinou por muitos anos a economia política da colônia.

A cocaína, por sua vez, com profundas raízes na pré-história, traz uma íntima relação com o período colonial, porém não há nenhum museu dedicado a ela, ou à relação que há entre ela e o "poporo quimbaya”, como objeto para uso de coca durante cerimônias religiosas. Michael Taussig (2013, p. 18) argumenta que "não falar da cocaína, não a exibir, é continuar com a mesma negação da realidade que o Museu do Ouro pratica com a escravidão". O Museu do Ouro se sedimenta em bases iconológicas, o outro, ou seja, o museu da cocaína, é obliterado e negligenciado por tais sedimentos. Cabe, portanto, ao estudioso-arqueólogo perscrutar as camadas até então intocadas, como gesto de abertura dos museus a um novo uso.

Gérard Wacjman, em "A arte, a psicanálise, o século", investiga o século XX a partir de uma singularidade, que, por sua vez, abre um espaço heterogêneo, repleto de multiplicidades. Como ele argumenta no ensaio em questão, "há fortes razões para se dizer que o século XX terá sido o século do objeto, ou dos objetos, plurais, múltiplos" (WACJMAN, 2012, p. 55). No entanto, entre a enorme massa de objetos produzidos no século passado, qual seria o objeto do século dos objetos? O século $\mathrm{XX}$, ou o século das grandes guerras, ou ainda, das guerras em série, impôs o regime da lógica dualista em que um dos termos será derrotado, configurando, portanto, a lógica da unidade. Dito de outra forma: o século XX foi o século da pretensão de Totalidade (com todas as singularidades de seus totalitarismos).

Arte e literatura, quando não submetidas a essa lógica, parecem nos propor um modo de montagem de séries não mais construídas por um único modelo, pois se cada gesto artístico traz em si singularidades, estas se efetivam na medida em que as relacionamos com outras singularidades. Nesse caso, rompe-se com a pretensão de totalidade, cabendo ao 
espectador, leitor, crítico, estabelecer relações que podem parecer disparatadas. Tal postura pretende lidar, ao mesmo tempo, de modo ambivalente, com as multiplicidades e singularidades não mais de um objeto, mas muito mais com as multiplicidades e singularidades de um gesto ético e estético inscrito no corpo do artista - e, por que não, no corpo dos Museus -, gesto que fala tagarelamente de algo que falta em seu lugar. Ainda como aponta Wacjman (2012, p. 57), "o objeto que melhor caracterizaria o século XX é a ruína”. Há na ruína algo que fala compulsivamente e que se encontra, não por acaso, diante de nós. Assim, é necessário colocar-se à escuta da ruína, pois ela "é o objeto-porquanto-ele-fala, o objeto que se tornou tagarela, desgastado pela conversa banal, reduzido ao estado de traço" (p. 57).

Em última análise, no que resta menos a partir do movimento temporal dos museus se encontra uma abertura à democracia, visto que os museus não são países, mas sim, rios.

\section{$\overline{\text { REFERÊNCIAS }}$}

ADORNO, Theodor W. Museu Valéry Proust. In: Prismas: crítica cultural e sociedade. Trad. Augustin Wernet e Jorge Mattos Brito de Almeida. São Paulo: Ática, 1998, pp. $173-185$.

AGAMBEN, Giorgio. Profanações. Trad. Selvino J. Assmann. São Paulo: Boitempo, 2007.

ANDRADE, Mário de. A enciclopédia brasileira. São Paulo: Edusp, 1993.

BRANDI, Cesare. A passo d'uomo. Milano: Bompiani, 1970a.

BRANDI, Cesare. Le due vie. Bari: Editori Laterza, 1970b.

BRANDI, Cesare. Scritti sull'arte contemporanea. Torino: Giulio Einaudi editore, 1976.

BRANDI, Cesare. Verde Nilo. Roma: Editori Riuniti, 1991.

BRANDINI, Laura Taddei (org.). Crônicas e outros escritos de Tarsila do Amaral. Campinas: Editora da Unicamp, 2008.

TAUSSIG, Michael. Mi museo de la cocaína. Trad. Cristóbal Gnecco. Popayán: Universidad del Cauca, 2013.

VALÉRY, Paul. O problema dos museus. Trad. Sônia Salzstein. ARS, São Paulo, v. 6, n. 12, 2008, pp. 31-33. 
WACJMAN, Gérard. A arte, a psicanálise, o século. In: IANNINI, Gilson; VILELA, Yolanda (orgs.). Lacan, o escrito, a imagem. Trad. Yolanda Vilela. Belo Horizonte: Autêntica Editora, 2012, p. 55.

Recebido: 28/11/2018

Aceito: 26/04/2019

Publicado: 1/07/2019

Remate de Males, Campinas-SP, v.39, n.1, pp. 28-37, jan./jun. 2019 - 37 